\title{
Photocatalytic Degradation of Methylene Blue using Zinc Oxide Synthesized by Hydrothermal Method
}

\author{
${ }^{* 1}$ Hande BEK, Ozge Nur BALCI, ${ }^{1}$ Ayse Gul TURE, ${ }^{2} \mathrm{M}$. Turkay AYDIN and ${ }^{1}$ Halit L. HOSGUN \\ ${ }^{*}$ Faculty of Engineering and Natural Science, Department of Chemical Engineering, Bursa Technical University, \\ Bursa, TURKEY. \\ ${ }^{2}$ Faculty of Science, Department of Physics, Eskişehir Technical University, Eskişehir, TURKEY.
}

\begin{abstract}
$\mathrm{ZnO}$ nanoparticals ( $\mathrm{ZnO}-\mathrm{NPs}$ ) were synthesized by hydrothermal method at low temperatures over a range of different hydrothermal time periods and different calcination temperatures. The synthesized ZnO-NPs were characterized by X-ray diffraction (XRD), scanning electron microscopy (SEM), and nitrogen adsorption-desorption isotherms (BET). The XRD results showed that all ZnO-NPs were hexagonal wurtzite phase. The photocatalytic activities of the ZnO-NPs were tested through the degradation of methylene blue under UV light. The highest methylene blue (MB) degradation was found to be $99 \%$ with zinc oxide synthesized at 48 hours hydrothermal process time and $300{ }^{\circ} \mathrm{C}$ calcination temperature conditions during 3 hours degredation time. As a result, the synthesized by hydrothermal method at low temperatures $\mathrm{ZnO}$-NPs have potential applications in the treatment of wastewater.
\end{abstract}

Key words: Zinc oxide, hydrothermal synthesis, photocatalysis, methylene blue, photodegradation.

\section{Introduction}

Zinc oxide $(\mathrm{ZnO})$ is the most important material in scientific research and industrial applications with the unique properties such as wide transmission bandwidth, a large bonding energy and a high permeability in the $0.4-2 \mu$ optical wavelength range at room temperature. Therefore, it is used in sensors [1-4], transducers [5-7], generators [8-10], photocatalysts [11-13], laser and diodes [14]. The applications of $\mathrm{ZnO}$ are strongly dependent on its own morphology and size of particles. Various methods such as hydrothermal, chemical vapor deposition, sol-gel, electrospinning, spray prolysis, vapor transport method, chemical precipitation are used for the synthesis of zinc oxide. Among these methods, hydrothermal method is mostly preferred due to it is low cost, practical, ability to be chemically controlled, obtain a uniform product, avoid the need for processes such as high temperatures and grinding [15-16].

In this study, $\mathrm{ZnO}$ nanoparticles were synthesized by hydrothermal method. The effects of hydrothermal synthesis time and calcination temperature were selected as parameters. The characterization of the synthesized samples were performed by SEM (Scanning electron microscope), BET (Brunauer-Emmett-Teller) and XRD (X-ray diffraction) analyzes. Degradation of methylene blue was carried out in home-made UV reactor to investigate photocatalytic activity.

* Hande BEK: Address: Faculty of Engineering and Natural Science, Department of Chemical Engineering Bursa Technical University, 16310, Bursa TURKEY. E-mail address: handebek96@hotmail.com, Phone: +902243003493. 


\section{Materials and Method}

\subsection{Materials}

All the chemicals purchased and used without any further purification as follows: Zinc nitrate hexahydrate $\left(\mathrm{Zn}\left(\mathrm{NO}_{3}\right)_{2} .6 \mathrm{H}_{2} \mathrm{O}\right)$ : Sigma Aldrich (98\%), ammonium hydroxide solution $\left(\mathrm{NH}_{4} \mathrm{OH}\right)$ : Sigma-Aldrich (25-30\%), sodium hydroxide (NaOH): Sigma-Aldrich (98\%), methylene blue $\left(\mathrm{C}_{16} \mathrm{H}_{18} \mathrm{ClN}_{3} \mathrm{~S}\right)$ : Merck, methanol $\left(\mathrm{CH}_{3} \mathrm{OH}\right)$ : Merck $(98 \%)$. Distilled water was used for all the experimental steps.

\subsection{Hydrothemal synthesis of zinc oxide nanoparticals}

In order to synthesis $\mathrm{ZnO}-\mathrm{NPs}, 2 \mathrm{~g} \mathrm{Zn}\left(\mathrm{NO}_{3}\right)_{2} \cdot 6 \mathrm{H}_{2} \mathrm{O}$ was firstly dissolved in mixture of $0.15 \mathrm{M}$ $\mathrm{NH}_{4} \mathrm{OH}(45 \mathrm{ml})$ and distilled water $(100 \mathrm{ml})$. The mixture was stirred for 30 minutes and $\mathrm{NaOH}$ was added until the $\mathrm{pH}$ of the solution reached 9-10. Then solution was transferred into a $250 \mathrm{~mL}$ Schott glass for hydrothermal process. The mixture kept in a furnace at $60{ }^{\circ} \mathrm{C}$ with different time periods $(24,48,72,96 \mathrm{~h})$. After the hydrothermal process, the white precipitate was centrifuged and washed with distilled water and methanol, respectively. The final precipitate was dried at 60 ${ }^{\circ} \mathrm{C}$ for $12 \mathrm{~h}$, and then calcined in air at different temperatures $\left(180,300,400,500{ }^{\circ} \mathrm{C}\right)$ for $1 \mathrm{~h}$. Figure 1 shows the synthesis flow diagram of the $\mathrm{ZnO}-\mathrm{NPs}$.

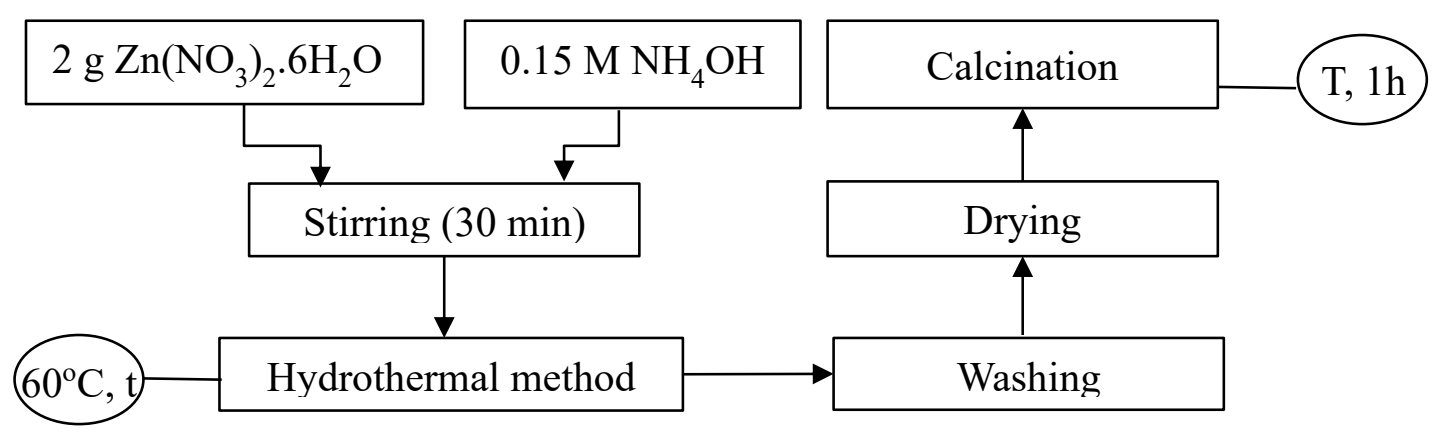

Fig 1. Flow diagram of the preparation steps of $\mathrm{ZnO}-\mathrm{NPs}$.

\subsection{Photocatalytic degredation}

The photocatalytic activity of $\mathrm{ZnO}-\mathrm{NPs}$ were investigated by photocatalytic degradation of aqueous methylene blue (MB) solution. The photocatalytic degradation tests of $\mathrm{MB}$ were performed in a home-made photoreactor which containing four UV-C lamps of $11 \mathrm{~W}$ each as shown in Figure 2. In a typical experiment, $0.25 \mathrm{~g}$ of the $\mathrm{ZnO}-\mathrm{NPs}$ was dispersed in $100 \mathrm{~mL}$ of $\mathrm{MB}$ (20 ppm concentration) under the constant stirring speed. At the beginning of the experiments, suspension stirred in dark conditions in order to reach an adsorption-desorption equilibrium. Periodically, a sample of $5 \mathrm{~mL}$ of reaction mixture was withdrawn, centrifuged and the $\mathrm{MB}$ concentrations determined by spectrophotometrically. 


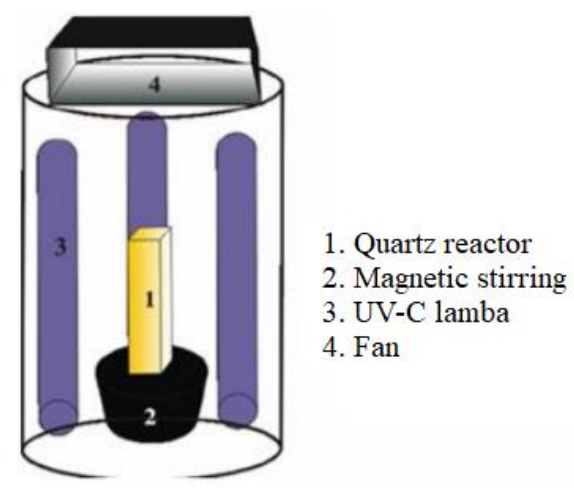

Fig 2. Schematic representation of the home-made photoreactor

The efficiency of photocatalytic degredation can be calculated using Equation (1). Where $\mathrm{A}_{0}$ is the initial absorbance value of $\mathrm{MB}$ solution and $\mathrm{A}$ is the absorbance value of MB solution after the irradiation time ' $\mathrm{t}$ '.

$$
n(\%)=\left(\left(A_{0}-A\right) / A_{0}\right) \times 100
$$

\subsection{Characterization}

XRD patterns of ZnO-NPs were carried out by using an X-ray diffractometer (XRD, D8 Advance, Bruker Instrument Co., Ltd., Germany) with monochromatic $\mathrm{Cu}-\mathrm{K} \alpha$ radiation $\lambda=1.5406$ at a scan speed of $0.5^{\circ} / \mathrm{min}$ over a $2 \theta$ range of $20^{\circ}-70^{\circ}$. Microstructural features of the ZnO NPs were investigated by using a field emission gun scanning electron microscopy (FESEM, ZEISS Ultraplus). Nitrogen adsorption and desorption isotherms were measured using a porosimeter (Micromeritics, TriStar II) at $77 \mathrm{~K}$. Prior to adsorption, the ZnO-NPs were outgassed at $150{ }^{\circ} \mathrm{C}$ for $24 \mathrm{~h}$ under vacuum. Measurements of MB concentrations were performed by an UV-Vis spectrophotometer (Agilent - CARY60) with wavelength 200-800 nm.

\section{Results}

\subsection{Effect of hydrothermal process time}

The crystal structures of ZnO-NPs synthesized hydrothermal method were characterized by XRD (Fig. 3). The main diffraction peaks are observed at $\sim 32^{\circ}, \sim 35^{\circ}, \sim 36^{\circ}, \sim 47^{\circ}, \sim 56^{\circ}, \sim 64^{\circ}, \sim 66^{\circ}$, $\sim 68^{\circ}$ were indexed as $\left(\begin{array}{lll}1 & 0 & 0\end{array}\right),\left(\begin{array}{lll}0 & 0 & 2\end{array}\right),\left(\begin{array}{lll}1 & 0 & 1\end{array}\right),\left(\begin{array}{lll}1 & 0 & 2\end{array}\right),\left(\begin{array}{lll}1 & 1 & 0\end{array}\right),\left(\begin{array}{lll}1 & 0 & 3\end{array}\right),\left(\begin{array}{lll}2 & 0 & 0\end{array}\right)$ and $\left(\begin{array}{lll}1 & 1 & 2\end{array}\right)$ hkl crystal planes. All the main diffraction peaks in the patterns of the ZnO-NPs fitted the diffraction peaks of hexagonal wurtzite structure of the zinc oxide. 


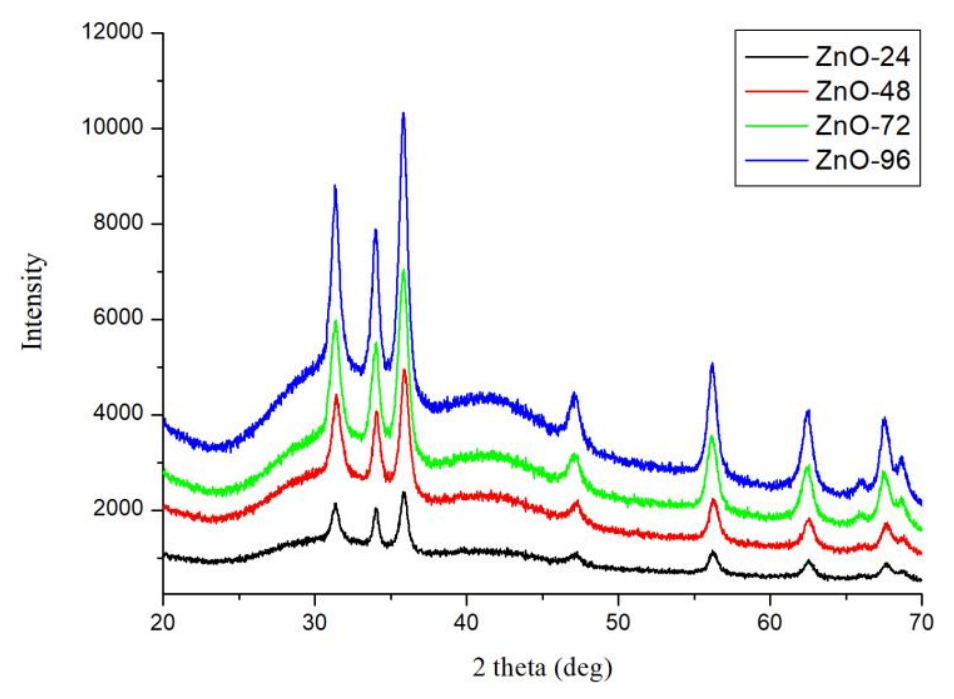

Fig. 3. XRD patterns of ZnO-NPs synthesized at $60^{\circ} \mathrm{C}$ with different time periods

SEM analysis was used to investigate the structural morphology of the ZnO-NPs. SEM images of samples show that the particles are uniform in shape and well dispersed (Fig.4.).

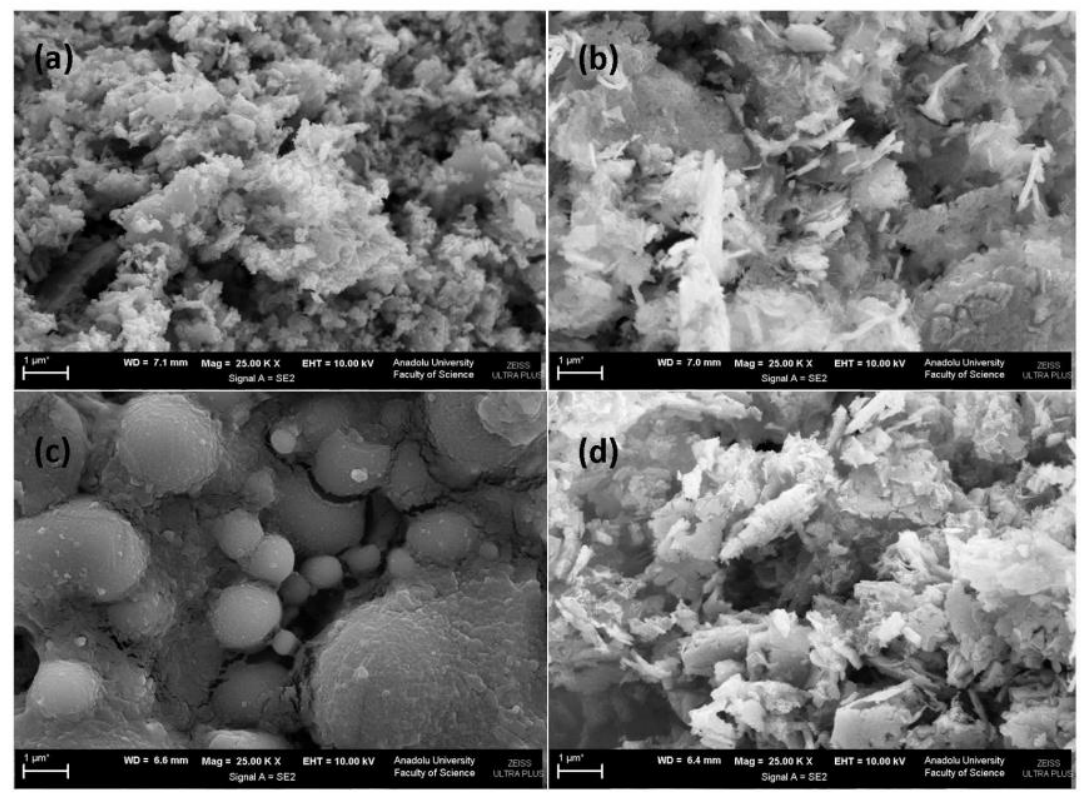

Fig. 4. SEM images of $\mathrm{ZnO}-\mathrm{NPs}$ a) $\mathrm{ZnO}-24$, b) $\mathrm{ZnO}-48$, c) $\mathrm{ZnO}-72$, d) $\mathrm{ZnO}-96$.

The surface area, pore volume, and pore diameter of the ZnO-NPs are listed in Table 1. As can be seen from Table 1 increasing the hydrothermal process time from $24 \mathrm{hr}$ to $48 \mathrm{hr}$, the surface area increased almost five-fold. But the increasing the hydrothermal process time from $48 \mathrm{hr}$ to $96 \mathrm{hr}$, Surface area decreased from $76 \mathrm{~m}^{2} / \mathrm{g}$ to almost $30 \mathrm{~m}^{2} / \mathrm{g}$. 
Table 1. The Effect of hydrothermal time on the textural properties of the ZnO-NPs

\begin{tabular}{cccc}
\hline Samples & $\begin{array}{c}\text { Surface area } \\
\left(\mathrm{m}^{2} / \mathrm{g}\right)\end{array}$ & $\begin{array}{c}\text { Pore Volume } \\
\left(\mathrm{cm}^{3} / \mathrm{g}\right)\end{array}$ & $\begin{array}{c}\text { Pore diameter } \\
(\AA)\end{array}$ \\
\hline $\mathrm{ZnO}-24$ & 15.719 & 0.061 & 170.018 \\
$\mathrm{ZnO}-48$ & 76.145 & 0.324 & 177.562 \\
$\mathrm{ZnO}-72$ & 31.874 & 0.135 & 194.046 \\
$\mathrm{ZnO}-96$ & 28.145 & 0.163 & 261.660 \\
\hline
\end{tabular}

Figure 5 shows the effect of hydrothermal time on the photocatalytic activity of ZnO-NPs for the MB under the UV light. It's clearly indicated that lowest MB degradation was reached by ZnO-24 synthesized at $60{ }^{\circ} \mathrm{C}$ for 24 hours (Fig. 5a) and highest MB degradation was in ZnO-48 synthesized at $60{ }^{\circ} \mathrm{C}$ for 48 hours (Fig. 5b).

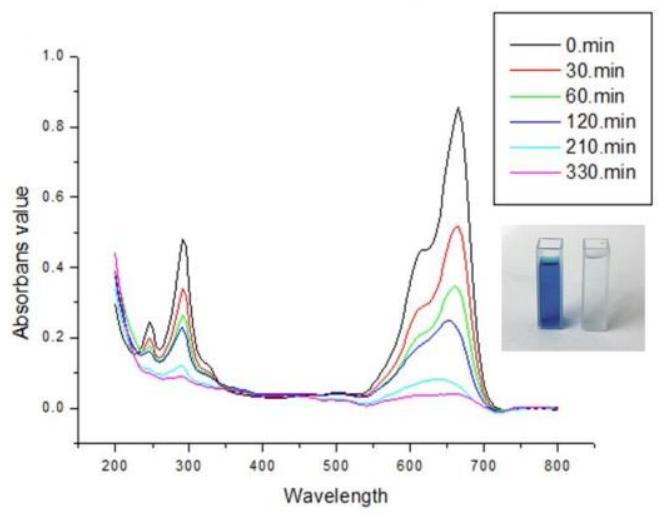

(a)

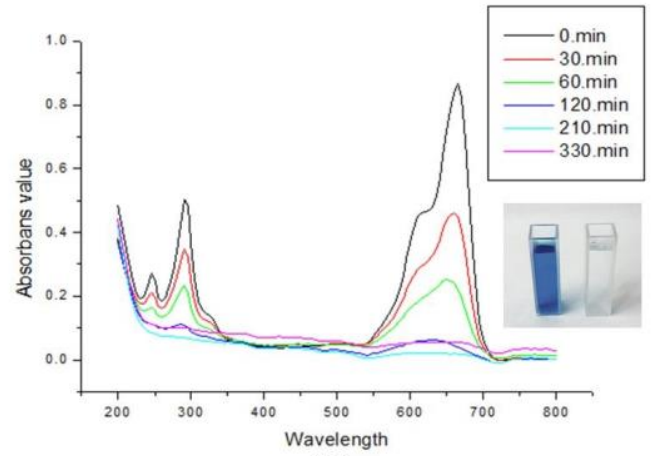

(c)

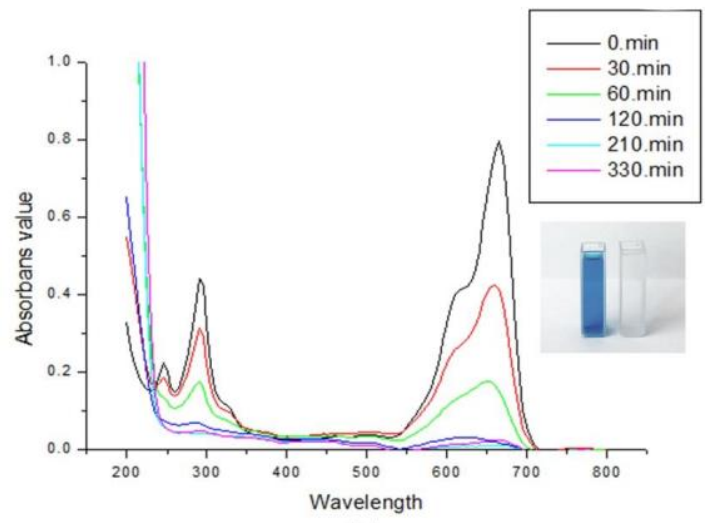

(b)

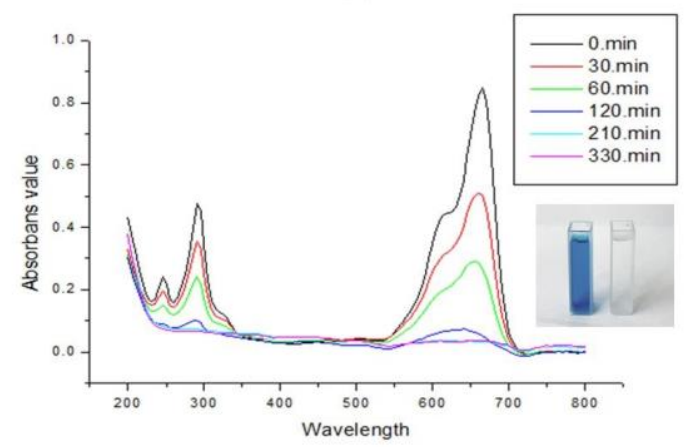

(d)

Fig. 5. The effect of hydrothermal treatment time on absorption spectral changes in $\mathrm{MB}$ a) $\mathrm{ZnO}-24$, b) $\mathrm{ZnO}-48$, c)

$$
\mathrm{ZnO}-72 \text {, d) } \mathrm{ZnO}-96
$$

While the degredation time increases, the efficiency of photocatalytic degredation reaches a fixed value after a certain time (Table 2). The $\mathrm{ZnO}-48$ synthesized at $60{ }^{\circ} \mathrm{C}$ for 48 hours provides faster photocatalytic degredation and $98.43 \%$ decomposition efficiency compared to other samples. So the optimal hydrothermal synthesis time of the ZnO-NPs is seen to be 48 hours. 
Table 2. The efficiency of photocatalytic degredation of the ZnO-NPs

\begin{tabular}{ccccc}
\hline Time (min) & ZnO-24 & ZnO-48 & ZnO-72 & ZnO-96 \\
\hline 30 & $40.22 \%$ & $46.98 \%$ & $47.76 \%$ & $40.77 \%$ \\
60 & $59.49 \%$ & $77.84 \%$ & $70.92 \%$ & $65.48 \%$ \\
120 & $71.34 \%$ & $96.49 \%$ & $92.32 \%$ & $91.44 \%$ \\
210 & $90.50 \%$ & $98.42 \%$ & $98.29 \%$ & $95.71 \%$ \\
330 & $90.53 \%$ & $98.43 \%$ & $98.30 \%$ & $95.72 \%$ \\
\hline
\end{tabular}

\subsection{Effect of calcination temperature}

According to results obtained by the effect of hydrothermal process time, experiments were performed at $60 \mathrm{C}$ and $48 \mathrm{hr}$ hydrothermal process time.

The crystal structures of $\mathrm{ZnO}-\mathrm{NPs}$ synthesized at different calcination temperature were shown in Fig. 6. The main diffraction peaks are observed at $\sim 32^{\circ}, \sim 35^{\circ}, 47^{\circ}, \sim 56^{\circ}, \sim 64^{\circ}$. All the main diffraction peaks in the patterns of the ZnO-NPs synthesized at different calcination temperature also fitted the diffraction peaks of hexagonal wurtzite structure of the zinc oxide.

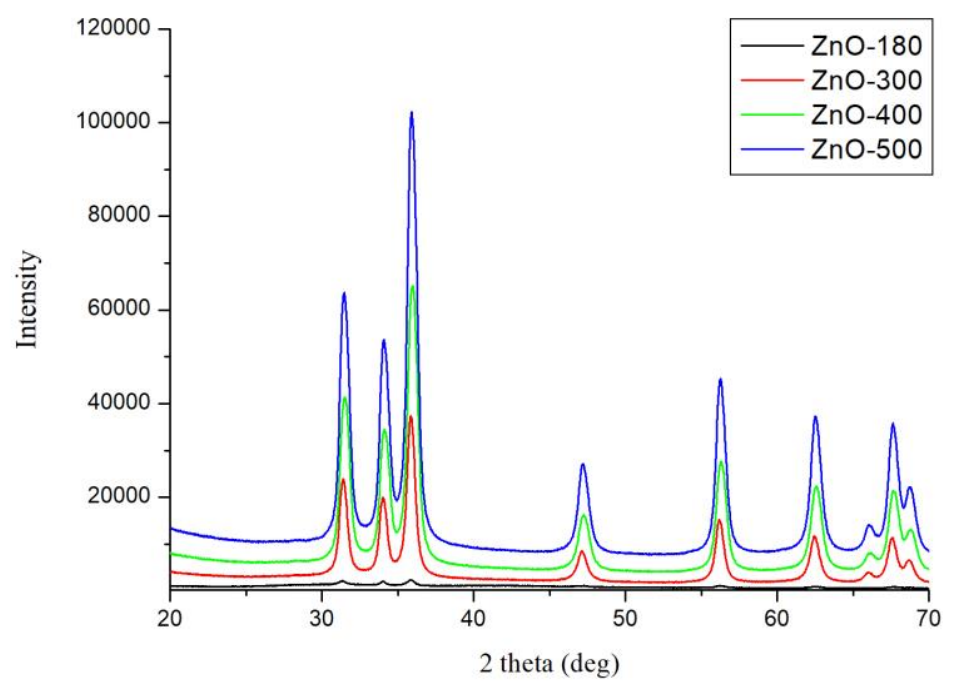

Fig. 6. XRD patterns of $\mathrm{ZnO}-\mathrm{NPs}$ the calcined in air at different temperatures

The effect of calcination temperature on the surface area, pore volume, and pore diameter of the $\mathrm{ZnO}-\mathrm{NPs}$ are listed in Table 3. As can be seen from Table 3, increasing the calcination temperature, the surface area and pore volume decreased. 
Table 3. Effect of calcination temperature on textural properties of the ZnO-NPs

\begin{tabular}{cccc}
\hline Samples & $\begin{array}{c}\text { Surface area } \\
\left(\mathrm{m}^{2} / \mathrm{g}\right)\end{array}$ & $\begin{array}{c}\text { Pore Volume } \\
\left(\mathrm{cm}^{3} / \mathrm{g}\right)\end{array}$ & $\begin{array}{c}\text { Pore diameter } \\
(\AA)\end{array}$ \\
\hline $\mathrm{ZnO}-180$ & 76.145 & 0.324 & 177.562 \\
$\mathrm{ZnO}-300$ & 16.406 & 0.074 & 185.284 \\
$\mathrm{ZnO}-400$ & 7.694 & 0.059 & 321.945 \\
$\mathrm{ZnO-500}$ & 4.127 & 0.035 & 199.526 \\
\hline
\end{tabular}

When the calcination temperature increases, the degredation percentages increase as it is seen in Figure 7. The $\mathrm{ZnO}-300$ calcined at $300{ }^{\circ} \mathrm{C}$ for 1 hours provides faster photocatalytic degredation and $98.94 \%$ decomposition efficiency compared to other samples (Table 4). So the optimal calcined temperature of the $\mathrm{ZnO}-\mathrm{NPs}$ is determined to be $300{ }^{\circ} \mathrm{C}$.

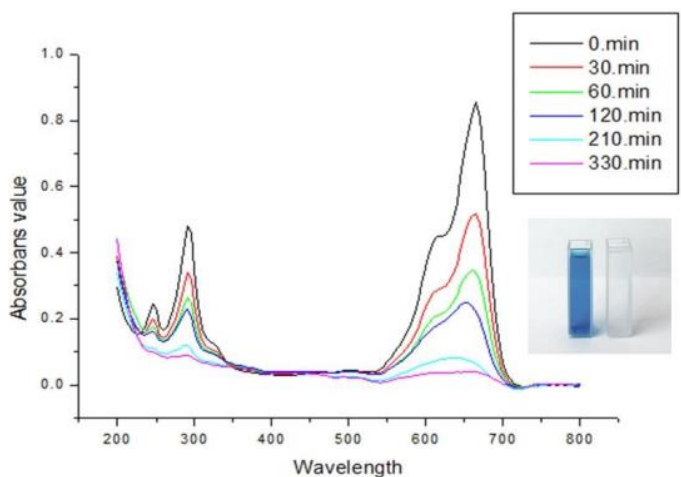

(a)

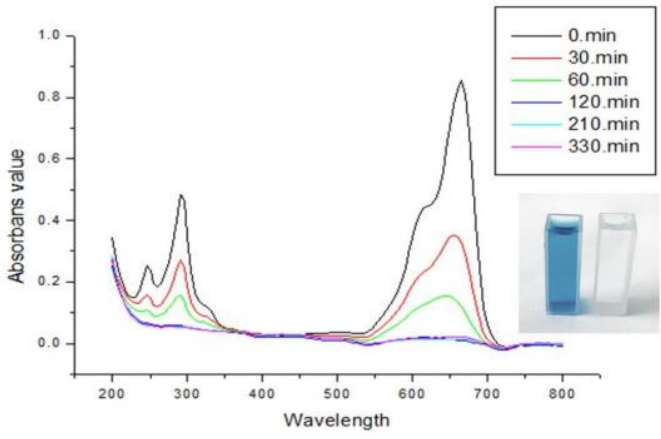

(c)

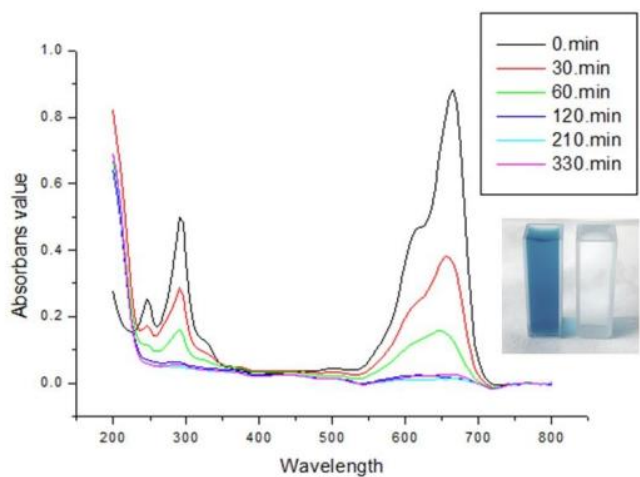

(b)

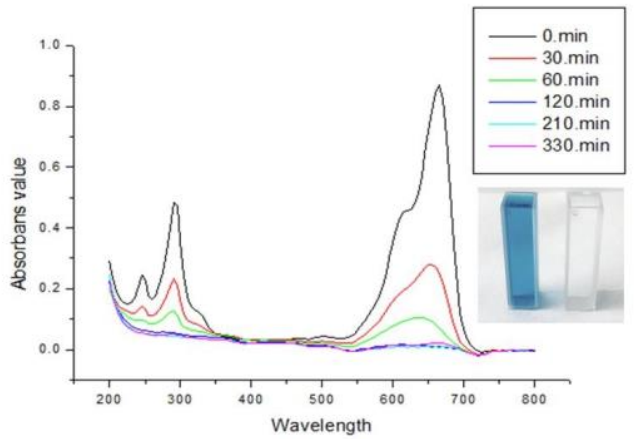

(d)

Fig. 7. The effect of calcined temperature on absorption spectral changes in $\mathrm{MB}$ a) $\mathrm{ZnO}-180$, b) $\mathrm{ZnO}-300$, c) $\mathrm{ZnO}$ 400, d) ZnO-500 
Table 4. The efficiency of photocatalytic degredation of the ZnO-NPs

\begin{tabular}{ccccc}
\hline Time (min) & ZnO-180 & ZnO-300 & ZnO-400 & ZnO-500 \\
\hline 30 & $40.22 \%$ & $58.92 \%$ & $56.78 \%$ & $13.77 \%$ \\
60 & $59.49 \%$ & $83.04 \%$ & $82.08 \%$ & $29.72 \%$ \\
120 & $71.34 \%$ & $98.08 \%$ & $97.68 \%$ & $54.32 \%$ \\
210 & $90.50 \%$ & $98.94 \%$ & $98.36 \%$ & $76.34 \%$ \\
330 & $90.53 \%$ & $98.95 \%$ & $98.36 \%$ & $90.45 \%$ \\
\hline
\end{tabular}

\section{Discussion}

For the hydrothermal synthesis of zinc nanoparticles, two parameters were determined in this study: hydrothermal time and calcination temperature. The changes in surface and crystal properties were investigated when the hydrothermal time was increased from 24 hours to 96 hours. The surface area increased almost 5 times when the hydrothermal process time was increased from 24 hours to 48 hours. Then increasing the hydrothermal process time up to 96 hours reduced the surface area. This is consistent with photocatalytic activity. The highest MB degradation was obtained with the materials synthesized in hydrothermal process time of 48 hours. On the other hand, the surface area was decreased by increasing the calcination temperature. However, there is no correlation between MB degradation and surface area. The highest MB degradation was obtained with the samples calcined at 300 and $400{ }^{\circ} \mathrm{C}$. This can be explained by the improvement of the crystal structure in this temperature range.

\section{Conclusions}

The hydrothermal method described in this study has proved to be a successful and green method for the synthesis of $\mathrm{ZnO}$-NPs at low temperature. The experimental results indicated that the morphology of ZnO-NPs was influenced by hydrothermal treatment time and calcined temperature. The highest MB degradation (99\%) was achieved with zinc nanoparticles synthesized at 48 hours hydrothermal time and $300{ }^{\circ} \mathrm{C}$ calcination temperature conditions. The study provides a rapid, lowcost and efficient approach for the degradation of organic dye and could be envisioned further for waste water purification.

\section{References}

[1] Hsiao C.C., Huang K.Y., Hu, Y.C. Fabrication of a ZnO Pyroelectric Sensor. Sensors 2008; 8 (1): 185-192.

[2] Barreca D., Bekermann D., Comini E., Devi A., Fischer R. A.; Gasparotto, A. et al. 1D ZnO nanoassemblies by Plasma-CVD as chemical sensors for flammable and toxic gases. Sensors and Actuators B: Chemical 2010; 149 (1): 17.

[3] Rodriguez J. A., Jirsak T., Dvorak J., Sambasivan S., Fischer D. Reaction of $\mathrm{NO}_{2}$ with $\mathrm{Zn}$ and ZnO: Photoemission, XANES, and Density Functional Studies on the Formation of $\mathrm{NO}_{3}$. J. Phys. Chem. Lett 1999; 104 (2): 319-328.

[4] Huang J., Wu Y., Gu C., Zhai M., Yu K., Yang M., Liu J. Large-scale synthesis of flowerlike 
$\mathrm{ZnO}$ nanostructure by a simple chemical solution route and its gas-sensing property. Sensors and Actuators B: Chemical 2010; 146 (1): 206-212.

[5] Fred S. H. In Evaluating Optical Contact Bonds Using Thin Film ZnO Transducers, International Frequency Control Symposium and Exposition, 2006; 338-342.

[6] Mason A. D., Huang C. C., Kondo S., Koesdjojo M. T., Tennico Y. H., Remcho V. T. et al. Synthesis, Functionalization and Environmental Stabilization of $\mathrm{ZnO}$ Nanobridge Transducers for Gas and Liquid-phase Sensing. Sensors and Actuators B: Chemical 2011; 155 (1): 245-252.

[7] Aeugle T., Bialas H., Heneka K., Pleyer W. Large area piezoelectric ZnO film transducers produced by r.f. diode sputtering. Thin Solid Films 1991; 201 (2): 293-304.

[8] Bourret-Courchesne E. D., Derenzo S. E., Weber M. J. Development of ZnO:Ga as an ultrafast scintillator. Nuclear Instruments and Methods in Physics Research A 2009; 602: 358363.

[9] Chang W.T., Chen Y.C., Lin R.C., Cheng C.C., Kao K.S., Wu B.R. et al. Design and fabrication of a piezoelectric transducer for wind-power generator. Thin Solid Films 2011; 519 (15): 4687-4693.

[10] Neal J.S., Boatner L. A., Giles N. C., Halliburton L. E., Derenzo S. E., Bourret-Courchesne E. D. Comparative investigation of the performance of $\mathrm{ZnO}$-based scintillators for use as $\alpha$ particle detectors. Nuclear Instruments and Methods in Physics Research Section A 2006; 568 (2): 803-809.

[11] Behnajady M.A., Modirshahla N., Hamzavi R. Kinetic study on photocatalytic degradation of C.I. Acid Yellow 23 by ZnO photocatalyst. J. Hazard Mat. 2006; 133 (1-3):226-232.

[12] Tian C., Zhang Q., Wu A., Jiang M, Liang Z., Jianga B. et al. Cost-effective large-scale synthesis of $\mathrm{ZnO}$ photocatalyst with excellent performance for dye photodegradation. Chem. Commun. 2012; 48: 2858-2860.

[13] Reenamole G. R., Seery M. K., Pillai S.C. A Highly Efficient Ag-ZnO Photocatalyst: Synthesis, Properties, and Mechanism. J. Phys. Chem. C 2008; 112 (35): 13563-13570.

[14] Weintraub W., Zhou Z., Li Y., Deng Y. Solution synthesis of one-dimensional ZnO nanomaterials and their applications. Nanoscale 2010; 2(9): 1573-1587.

[15] Rezapour M., Talebian N. Mater Comparison of structural, optical properties and photocatalytic activity of $\mathrm{ZnO}$ with different morphologies: Effect of synthesis methods and reaction media. Chem. Phys. 2011; 129: 249.

[16] Jagadish C., Pearton. S. Zinc Oxide Bulk, Thin Films and Nanostructures, China: Elsevier. 